\title{
Molecular identification of leaf litter fungi potential for cellulose degradation
}

\author{
Waing KGD ${ }^{1 *}$, Gutierrez JM${ }^{1}$, Galvez $\mathrm{CT}^{2}$, Undan $\mathrm{JR}^{1}$ \\ ${ }^{1}$ Department of Biological Sciences, College of Arts and Sciences, Central Luzon State University, Science City of \\ Muñoz, Nueva Ecija, 3120 Philippines \\ ${ }^{2}$ Central Luzon State University, Science City of Muñoz, Nueva Ecija, Philippines 3120
}

Waing KGD, Gutierrez JM, Galvez CT, Undan JR 2015 - Molecular identification of leaf litter fungi potential for cellulose degradation. Mycosphere 6(2), 139-144, Doi $10.5943 /$ mycosphere/6/2/3

\begin{abstract}
In plant litter decomposition in forest ecosystem, fungi play a central role through nutrient cycling and humus formation in soil because they colonize the lignocellulose matrix in litter that other organisms are unable to decompose. It has been described that cellulase is an adaptive enzyme in most fungi and had the most common carbohydrate on earth. For this reason, the study provided information about the fungal species isolated in leaf litters contributing to its biodiversity database.

In this study, there are five species of fungi found to have cellulose degrading ability. The five species were identified using molecular approach and identified as Aspergillus eucalypticola, Aspergillus fumigatus, Colletotrichum gloeosporioides, Fusarium oxysporum and Penicilliun echinulatum. BLAST analysis showed the species of fungi ITS sequence from leaf litters, supported by $100 \%$ (A. fumigatus), $74 \%$ (A. eucalypticola), $100 \%$ (C. gloeosporioides), $100 \%$ (F. oxysporum) and $100 \%$ (P. echinolatum) sequence similarity.
\end{abstract}

Key words - Cellulase - cellulose - ITS - lignocellulose

\section{Introduction}

Leaf litter is a dead plant material like leaves that provides food and shelter to a variety of invertebrates that break down the leaves, which feeds the soil and other wildlife. In plant litter decomposition in forest ecosystem, fungi play a central role through nutrient cycling and humus formation in soil because they colonize the lignocelluloses matrix in litter that other organisms are unable to decompose (Swift et al. 1979, Kjøller \& Struwe 1982, Cooke \& Rayner 1984). Cellulases are a group of hydrolytic enzymes and are capable of degrading ligno-cellulosic materials having wide range of applications.

Fungi are important organisms involved in biogeochemical cycling within ecosystem and it is responsible for decomposing dead organic matter by reintroducing it into the environment. Because fungal decomposers play a significant role in carbon and nutrient cycling in ecosystems, it is important for biologists and other researchers to recognize fungal diversity associated with plant litter and other forms of decomposition. However, identification of specific fungal species had primarily been based on morphological means rather than the more efficient and accurate molecular techniques. 
Identification of the fungal species is based on mycelia i.e. color, size and shape and morphological characteristics such as conidia size and morphology of the conidiophores (Al-Hindi et al. 2011, Pitt \& Hocking 2009). These kinds of techniques in identification require skilled taxonomists. Minor differences in medium composition can impair effective comparison of mycelia characteristics (Larone 1995). The uses of fungal cultures, obtained from single spore isolations are fundamental to the identification of many fungi. In terms of the morphological species concept, cultures can provide extra characters for identification, and anamorph-teleomorph connections. Thus, the process of classifying and identifying fungi does not rely solely on morphological features for identification (Choi et al. 1999). New molecular and chemical methods for identifying fungi provide mycologists with new methodological tools for identifying fungal communities, such as rDNA gene sequencing (Kuehn 2008). Molecular practices have been used to classify a number of other organism species (Hebert et al. 2003). This method involves DNA extraction, polymerase chain reaction (PCR) with specific primers for fungi followed by gel-electrophoresis (Nikolcheva \& Barlocher 2003).

The ITS region is the most widely sequenced DNA region in molecular ecology of fungi (Peay et al. 2008) and has been recommended as the universal fungal barcode sequence (Schoch et al. 2012). It has typically been most useful for molecular systematics at the species level, and even within species. The ITS regions are located between the 18S and 28S rRNA genes and offer distinct advantages over other molecular targets including sensitivity due to the existence of approximately 100 copies per genome. The sequency variation of the ITS regions has led to their use in phylogenetic studies of many different organisms (Anaissie et al. 2009)

Thus, this research aimed to identify the different pre-isolated species of fungi present in leaf litters of three species of forest trees through the use of molecular techniques. Also, to evaluate and confirmed the cellulose degrading ability of the pre-isolated species of fungi.

\section{Materials \& Methods}

\section{Revival of cultures}

Fungi that were pre-isolated and identified morphologically in the leaf litter of clitorea, rain, and paper tree were inoculated using three-point inoculation method (three mycelia inoculums plated equidistantly from each other) (Fig. 1) in a sterilized Potato Dextrose Agar (PDA) and incubated until profuse growth was observed.

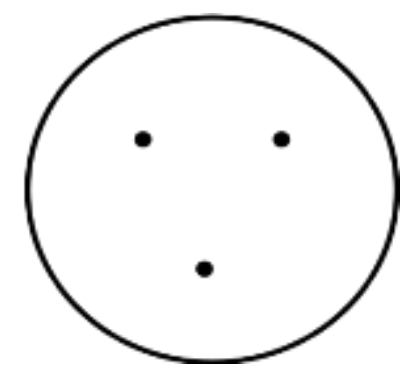

Fig. 1- Diagram of three-point inoculation method

\section{Evaluation for cellulose degrading ability}

Test fungi were inoculated using triple-point inoculation method in Carboxymethylcellulose (CMC) agar media (Hankin \& Anagnostakis 1975) and were incubated for 5 days. The CMC agar media was prepared by weighing $0.1 \mathrm{~g}$ of yeast extract, $0.5 \mathrm{~g}$ of peptone and $16 \mathrm{~g}$ of agar and dissolved in $100 \mathrm{~mL}$ distilled water supplemented with $0.5 \% \mathrm{Na}$-Carboxylmethycellulose then boiled until homogenous mixture was attained. After incubation period, plates were flooded with $0.2 \%$ congo red solution for 15 minutes and rinsed with $1 \mathrm{M} \mathrm{NaCl}$ solution for 15 minutes (Hankin \& Anagnostakis 1975). Cellulose degradation activities of fungal organisms were evaluated by measuring the clear zone around colonies on CMC agar on the $5^{\text {th }}$ day of incubation. 


\section{DNA extraction}

The DNA of the fungi was extracted from approximately $100 \mathrm{mg}$ of mycelia and was grinded with liquid nitrogen in a mortar and pestle. The samples were then placed in $2 \mathrm{ml}$ micro centrifuge tube. It was added with $750 \mu \mathrm{L}$ CTAB solution and $50 \mu \mathrm{L}$ of $20 \%$ sodium dodecyl sulfate (SDS) which was pre-warmed at $65^{\circ} \mathrm{C}$ then $600 \mu \mathrm{L}$ chloroform were added then mixed with vortex and incubated at $65^{\circ} \mathrm{C}$ for 30 minutes. After incubation, samples were subjected in a centrifuge at the speed of $10,000 \mathrm{rpm}$ for 30 minutes. The upper aqueous layer in the tube was transferred to a new $2 \mu \mathrm{L}$ microcentrifuge tube and $600 \mu \mathrm{L}$ ice cold isopropanol were added. It was incubated at $20^{\circ} \mathrm{C}$ for 24 hours. Samples were gently mixed and centrifuged at a speed of 10,000 rpm for 10 minutes. The supernatant was discarded and the pellets were washed by adding $500 \mu \mathrm{L}$ of $70 \%$ ethanol. Afterwards, it was mixed gently and centrifuged at 10,000 rpm for 10 minutes. Supernatant was discarded from the tubes and the remaining pellets were air-dried. Pellets were dissolved in $50 \mu \mathrm{L}$ TE buffer with RNAse. Two (2) $\mu \mathrm{L}$ of DNA were loaded at $0.8 \%$ agarose gel to check the quality. DNA quality and quantity was determined using Nano drop (ND2000, Thermo Scientific).

\section{PCR amplification and gel electrophoresis}

After DNA extraction, PCR amplification was performed on all samples using fungal specific primers ITS1 (Gardes \& Bruns 1993) and ITS2 (White et al. 1990). Wherein, $1 \mu \mathrm{L}$ of DNA were added into $24 \mu \mathrm{L}$ of the PCR components. The PCR components were composed of the following; $1 \mu \mathrm{L}$ of each primers (forward and reverse), $2 \mu \mathrm{L}$ of $\mathrm{MgCl}_{2}, 12.5 \mu \mathrm{L}$ of Taq Ready mix (KAPPA) and $7.5 \mu \mathrm{L}$ of $\mathrm{ddH}_{2} \mathrm{O}$ per $25-\mu \mathrm{L}$ reactions.

Each sample with the added components were placed in a $0.2 \mu \mathrm{L}$ PCR tube and then put in a thermocycler (Applied Biosystems 2720) which was initially set to $94{ }^{\circ} \mathrm{C}$ for 5 minutes for initial denaturation. Then, it is followed by 35 consecutive cycles of denaturation at $94{ }^{\circ} \mathrm{C}$ for 30 seconds, annealing at $55^{\circ} \mathrm{C}$ for 45 seconds, and primer extension at $72{ }^{\circ} \mathrm{C}$ for 45 seconds. Then, final phase of primer extension at $72{ }^{\circ} \mathrm{C}$ for 10 minutes and $10{ }^{\circ} \mathrm{C}$.

After amplification, the $2.0-\mu \mathrm{L}$ PCR products stained with gel red were loaded and run on a $1 \%$ agarose gel for 15 minutes. The amplified product was then purified using QIAquick PCR purification kit (QIAGEN).

\section{Sequence and BLAST analysis}

The PCR products were sent to $1^{\text {st }}$ Base Laboratory, Malaysia for sequencing. Available sequence similarity from databases was extracted using Basic Local Alignment Search Tool (BLAST) analysis and aligned using CLUSTAL W.

\section{Statistical analysis for cellulose degradation activity}

Screenings for cellulose activity were done by measuring the clear zones using digital vernier caliper and analyzed using Analysis of Variance. Comparison among means was done using Duncan Multiple Range Test (DMRT) at 5\% level of significance.

\section{Results}

A total of six species of fungi from leaf litters of clitorea tree, rain tree, and paper tree namely A. fumigatus, A. eucalypticola, A. niger, $C$. gloeosporioides, $F$. oxysporum and $P$. echinulatum were successfully revived and used for testing their ability to degrade cellulose. Out of the six species of fungi, five of them had potential for cellulose degradation and these were $A$. fumigatus, A. japonicus, C. gloeosporioides, F. oxysporum and P. echinulatum (Table 1, Fig. 2). The species of fungi that had the largest clear zones was $C$. gloeosporioides with a measured diameter of $16.66 \mathrm{~mm}$. F. oxysporum had $7.06 \mathrm{~mm}$ followed by A. eucalypticola, P. echinulatum and A. fumigatus with 5.21, 3.81, 3.81 and $2.62 \mathrm{~mm}$ of clear zone respectively. 
Table 1 Cellulose degradation activity of six pre-isolated leaf litter fungi after five days of incubation

\begin{tabular}{ll}
\hline Fungal organism & Diameter of clear zone (mm) \\
\hline Colletotrichum gloeosporioides & $16.66^{\mathrm{a}}$ \\
Fusarium oxysporum & $7.06^{\mathrm{b}}$ \\
Aspergillus eucalypticola & $5.21^{\mathrm{c}}$ \\
Penicillum echinulatum & $3.81^{\mathrm{cd}}$ \\
Aspergillus fumigatus & $2.62^{\mathrm{d}}$ \\
\hline
\end{tabular}

Values represent the mean measurement of the clear zones indicating cellulose activity produced by the pre-isolated leaf litter fungi. Means with the same letter superscript are not significantly different at $5 \%$ level of significance by DMRT.

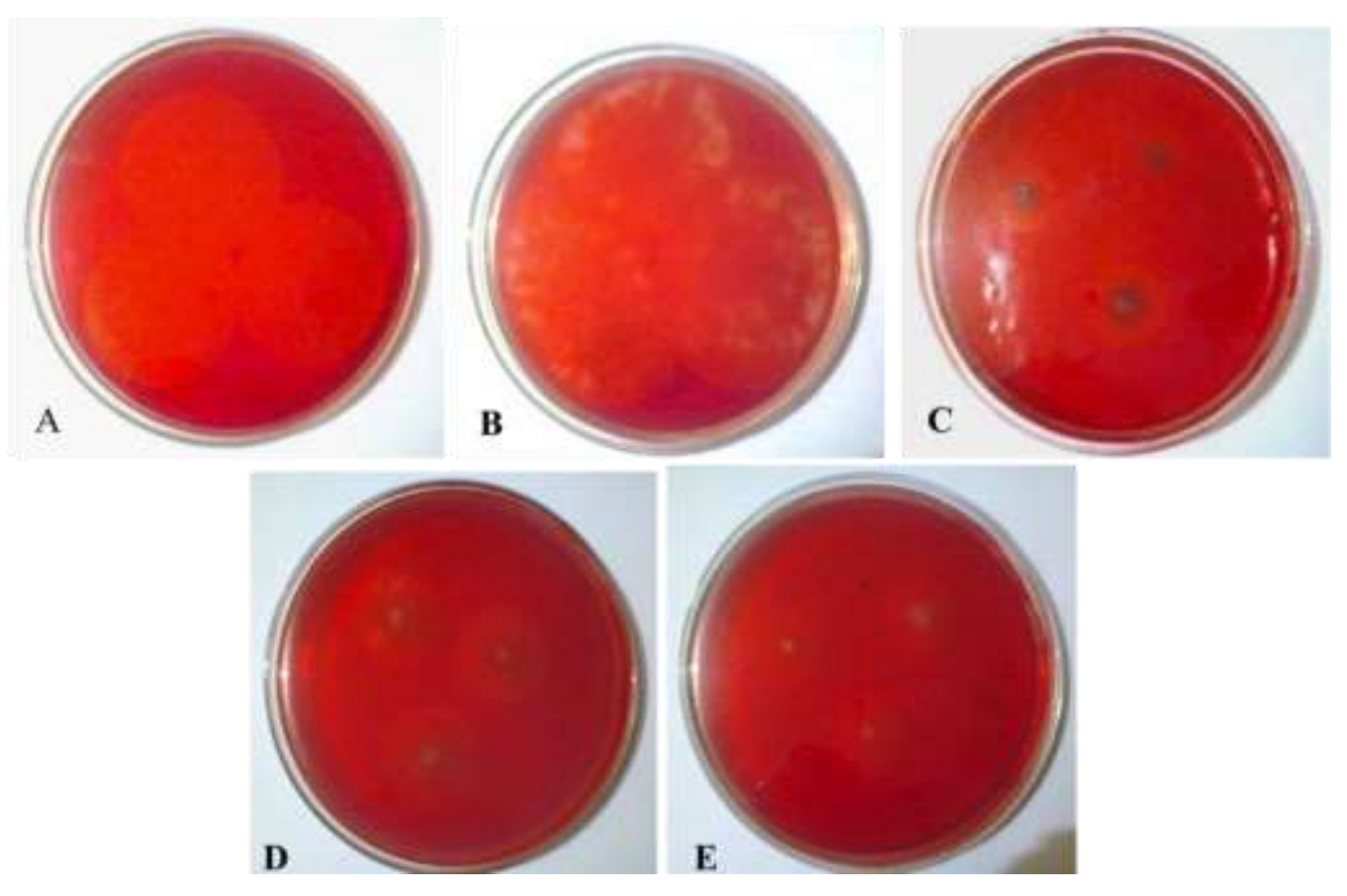

Fig 2 - Clear zones observed from the isolated leaf litter fungi potential for cellulose degradation. A C. gloeosporioides; B F. oxysporum; C A. eucalipticola; D P. echinolatum; E A. fumigatus

To confirmed the identity of the fungi isolated from leaf litters, the ITS region was amplified using ITS1 and ITS2 primer and were sequenced. The PCR products of the ITS region in the five different fungi were confirmed to be in range of approximately 450bp. Blast analysis revealed that fungal species were identified as P. echinolatum (KC692224.1) having 99\% maximum identity, A. fumigatus (KJ531960.1) with $100 \%$ identity, C. gloeosporioides (GU066620.1) with 100\% identity, A. eucalipticola (KC796400.1) with 100\% identity and F. oxysporum (KF914448.1) with 100\% identity, respectively (Table 2).

Table 2 Identities of the cultured fungi using BLAST with NCBI Genbank Accession Numbers

\begin{tabular}{lllll}
\hline Species & BP & Maximum Identity & Query & Genbank Accession Number \\
\hline P. echinulatum & 561 & $99 \%$ & $100 \%$ & KC692224.1 \\
A. fumigatus & 335 & $100 \%$ & $100 \%$ & KJ531960.1 \\
A. eucalypticola & 367 & $100 \%$ & $100 \%$ & KC796400.1 \\
C. gloeosporioides & 547 & $100 \%$ & $100 \%$ & GU066620.1 \\
F. oxysporum & 520 & $100 \%$ & $100 \%$ & KF914448.1 \\
\hline
\end{tabular}




\section{Discussion}

Six species of fungi from leaf litters of clitorea tree, rain tree, and paper tree were successfully revived namely A. fumigatus, A. japonicus, A. eucalypticola, C. gloeosporioides, $F$. oxysporum and $P$. echinolatum. Leaf litter decomposition is an important ecosystem-level process, which depends on the activity of microorganisms. Fungi convert leaf carbon into microbial biomass, enhancing leaf palatability and it is also considered the primary decomposers of dead plant biomass in terrestrial ecosystems. According to the studies of Pitchaimaru et al. (2008) and Sharma et al. (2007), the occurrence of various fungal species was higher for the species of Aspergillus and it was followed by the Alternaria, Fusarium and Penicillium.

Among the six species of fungi, five of which had the ability to degrade cellulose. These were A. fumigatus, A. euchalypticola, C. gloeosporioides, F. oxysporum and P. echinulatum. Productions of polysaccharide-degrading enzymes are common in fungal species of Aspergillus. It produces a wide spectrum of cell wall-degrading enzyme, allowing not only complete degradation of the polysaccharides but also tailored modifications by using specific enzymes purified from these fungi (de Vries \& Visser 2011). Species of Colletotrichum was able to grow and produce extracellular cellulolytic enzymes. Strain of Colletotrichum revealed that it had a good potential for the production of $\beta$-glucosidases, xylanases and $\beta$-xylosidases (Zimbardi et al. 2013). Several strain of Fusarium has been found to have a potential for converting not only D-zylose, but also cellulose to ethanol in a one-step process. Penicillium strains have the capability of secreting cellulolytic enzyme (Krogh et al. 2004).

The morphological and cultural features observed suggested that they most probably belong to genus Aspergillus, Colletotrichum, Fusarium and Penicillium. Nowadays, morphological and cultural characteristics are not enough to define the identity of the organism and the use of molecular phylogenetic analyses has increasingly common in the identification of fungal species (Win ko ko et al. 2011). Thus, molecular approach through blast analysis and phylogenetic analysis revealed that fungal species were; A. eucalypticola, A. fumigatus, $C$. gloeosporioides, $F$. oxysporum and $P$. echinolatum. This shows that, morphological based identification did not match molecular based identification among fungal species. The integration of morphology with molecular genetic markers represents a significant opportunity to study accurately the identity and phylogenetic relationships of fungi belonging to different family, which are commonly found in leaf litters.

This study evaluated and confirmed the cellulose degrading ability and identified the preisolated fungal species namely A. eucalypticola, A. fumigatus, C. gloeosporioides, $F$. oxysporum and $P$. echinulatum from leaf litters using molecular analysis. The molecular data supports the classification of the fungal species based on cultural and morphological characteristics.

\section{Acknowledgement}

The Commission on Higher Education of the Philippine Government financed this work.

\section{References}

Al-Hindi RR, Al-Najada AR, Mohamed SA. 2011 - Isolation and identification of some fruit spoilage fungi: screening of plant cell wall degrading enzymes. African Journal of Microbiology, 5 (4) (2011), Pp. 443-448.

Anaissie EJ, McGinnis MR, Pfaller MA. 2009 - Clinical Mycology. (second ed.) Churchill Livingstone (2009).

Choi YW, Hyde KD, Ho WH. 1999 - Single spore isolation of fungi. Fungal Diversity 3, 29-38.

Cooke RC, Rayner ADM. 1984 - Ecology of saprotropic fungi. London, UK: Longman. p. 415.

De Vries RP, Visser J. 2011 - Aspergillus enzymes involved in degradation of plant cell wall polysaccharides. doi: 10.1128/MMBR.65.4.497-522.2001 Microbiol. Mol. Bio. Rev. December 2001, 65, 4497-522.

Gardes M, Bruns TD. 1993 - ITS primers with enhanced specificity for basidiomycetes application to the identification of mycorrhizae and rusts. Mol Ecol 2:113-118. 
Hebert PDN, Cywinska A, Ball SL, De Waard JR. 2003 - Biological identifications through DNA barcodes. Proceedings of Royal Society 270, 313-321.

Hankin LH, Anagnostakis SL. 1975 - The use of solid media for the detection of enzyme production of fungi. Mycologia 67, 597-607.

Kjøller A, Struwe S. 1982 - Microfungi in ecosystems: fungal occurrence and activity in litter and soil. Oikos 39, 389-442.

Krogh KBR, Morkerberg A, Jorgensen H, Frisvad JC, Olsson L. 2004 - Screening of Genus Penicillium for producers of cellulolytic and xylanolytic enzymes. Biotechnology for Fuels and Chemicals 389-401.

Kuehn KA. 2008 - The role of fungi in the decomposition of emergent wetland plants. Pp. 19-41 in K.R. Sridhar, F. Bärlocher and K.D. Hyde (eds), Novel Techniques and Ideas in Mycology. Fungal Diversity Research Series 20, Fungal Diversity Press, Thailand.

Larone DH. 1995 - Medically Important Fungi: A Guide to Identification. (fourth ed.) ASM Press (1995).

Nikolcheva LG, Bärlocher F. 2003 - Molecular approaches to estimate fungal diversity. Terminal restriction fragment length polymorphism (T-RFLP). Pages 151-158. in: M.A.S. Graca, F. Bärlocher and M.O. Gessner (eds) Methods to Study Litter Decomposition: A Practical Guide. Springer, Dordrecht, the Netherlands.

Peay KG, Kennedy PG, Bruns TD. 2008 - Fungal Community Ecology: A hydrid beast with a molecular master. Bioscience 58, 799-810.

Pitchaimaru C, Venkatesan S, Muthuchelian K. 2008 - Litter fungi in Piranmalai Forest, Eastern Ghats, Tamilnadu, India. Ethnobotanical Leaflets 12, 750-57

Pitt JI, Hocking AD. 2009 - Fungi and Food Spoilage. (third ed.)SpringerLink: Springer e-Books (2009). Ramanathan G, Banupriya S, Abirami D. 2010-Production and optimization of cellulose from Fusarium oxysporum by submerge fermentation. Department of Microbiology 69, 454-459.

Schoch CL, Seifert KA, Huhndorf S, Robert V, Spouge JL, Andre Levesque C, Wen Chen. 2012 Nuclear ribosomal internal transcribed spacer (ITS) region as a universal DNA barcode marker for fungi. Proceedings of the National Academy of Sciences of the United States of America 109, 6241-6246.

Sharma G, Pandey RR, Tripathi SK, Singh AK. 2007 - Litterfall, litter decomposition and nutrient dynamics in a subtropical natural oak forest and management plantation in Northeastern India. Forest Ecology and Management 240, 96-104

Swift MJ, Heal OW, Anderson JM. 1979 - Decomposition in terrestrial ecosystem. Oxford, UK: Blackwell Scientific Publications. p. 372.

White TJ, Bruns TD, Lee SB, Taylor JW. 1990 - Amplification and direct sequencing of fungal ribosomal RNA genes for phylogenetics. In: Innis MA, Gelfand DH, Sninsky JJ, White TJ, editors. PCR protocols: a guide to methods and applications. United States: Academic Press. 315-322.

Win Ko Ko T, Stephenson SL, Bahkali AH, Hyde KD. 2011 - From morphology to molecular biology. Fungal diversity 50, 113-120.

Zimbardi LRL, Sehn C, Meleiro LP, Souza HM, Masui D, Nozawa MSF, Guimarães LHS, Jorge JA, Furriel RPM. 2013 - Optimization of $\beta$-Glucosidase, $\beta$-Xylosidase and Xylanase production by Colletotrichum graminicola under solid-state fermentation and application in raw sugarcane trash saccharification. Department of Chemistry. SP 14040-901. 